\title{
A pedagogia crítica e emancipatória/libertadora de inspiração freireana
}

\author{
Freire's critical and emancipatory pedagogy
}

\section{Pedagogía crítica y emancipadora inspirada en Freire}

\author{
Abdeljalil Akkari' \\ Universidade de Genebra, Suíça, Professor Ordinário (Titular) \\ https://orcid.org/0000-0002-4396-2635
}

Peri Mesquida ${ }^{2}$

Pontifícia Universidade Católica do Paraná, Professor Titular; Universidades de Genève e Fribourg, na Suiça, Professor visitante (inuité) https://orcid.org/0000-0003-4882-6808

Resumo: As ondas de refugiados migrados de diversas partes do mundo para a Europa, mas também para os Estados Unidos e para o Brasil, neste caso originários da Venezuela, em particular, e a forma como são tratados nos países que os "acolhem" nos motivaram a pensar no pensamento filosófico, político, social e pedagógico de Paulo Freire, a partir dos conceitos mais importantes. Este artigo objetiva desenvolver uma análise interpretativa, fundada na hermenêutica, em especial de Ricoeur (1989), da contribuição de Paulo Freire para os fundamentos teóricos e práticos da pedagogia crítica. Em primeiro lugar, analisamos o que, para nós, seriam os conceitos centrais da pedagogia freireana: opressão, conscientização, palavras geradoras, círculo de cultura, diálogo, práxis e emancipação. Em segundo lugar, destacamos a centralidade do "político" na pedagogia crítica de inspiração freireana, tanto em termos das políticas educacionais quanto no que diz respeito aos processos de aprendizagem. Em terceiro lugar, versamos as possibilidades de utilização da abordagem pedagógica de Freire na educação dos refugiados e dos estudantes que se encontram em situação de urgência e de conflitos. A pesquisa mostrou que a contribuição do pensamento de Freire para uma educação libertadora e amorosa e para a construção de uma sociedade colaborativa e acolhedora é inegável.

Palavras-chave: Freire. Pedagogia crítica. Politicas educacionais. Refugiados.

Abstract: The waves of refugees migrated from different parts of the world to Europe, but also to the United States and Brazil, in this case originating in Venezuela, in particular, and the way they are treated

Pós-doutor em Educação pelas Universidades de Genève e Fribourg; Doutor em Ciências da Educação pela Université de Genève, Suiça.

2 Pós-doutor pela Universidade de Baltimore (Estados Unidos); Doutor em Ciências da Educação pela Universidade de Genebra, Suiça. 
in the countries that "receive" them, motivated us to think about Paulo Freire's philosophical, political, social and pedagogical thinking, based on the most important concepts. This article aims to interpretative analyze based on hermeneutics, especially by Ricoeur (1989) Paulo Freire's contribution to the theoretical and practical foundations of critical pedagogy. First, we stress central concepts of Freire's pedagogy: oppression, consciousness, generative words, culture circle, dialogue, praxis and emancipation. Second, we highlight the centrality of the "political" in the critical pedagogy inspired by Freire, both in terms of educational policies and with regard to learning processes. Third, we I address the possibilities of using Freire's pedagogical approach in the education of refugees and students who are in emergencies contexts. The research showed that the contribution of Freire's thought to a liberating and loving education and to the construction of a collaborative and welcoming society, is undeniable.

Keywords: Freire. Critical pedagogy. Educational policies. Refugees.

Resumen: Las oleadas de refugiados emigraron de diferentes partes del mundo a Europa, pero también a los Estados Unidos y Brasil, en este caso originario de Venezuela, en particular, y la forma en que son tratados en los países que los acogen nos motivó a pensar en el pensamiento filosófico, político, social y pedagógico de Paulo Freire, basado en los conceptos más importantes. Este artículo tiene como objetivo desarrollar un análisis interpretativo, basado en la hermenéutica, especialmente por Ricoeur (1989), la contribución de Paulo Freire a los fundamentos teóricos y prácticos de la pedagogía crítica. Primero, analizaremos cuáles son los conceptos centrales de la pedagogía de Freire: opresión, conciencia, palabras generadoras, círculo cultural, diálogo, praxis y emancipación. En segundo lugar, destacaremos el rol central del aspecto "político" de la pedagogía crítica inspirada en Freire, tanto en términos de políticas educativas como en relación con los procesos de aprendizaje. Tercero, discutiremos las posibilidades de utilizar el enfoque pedagógico de Freire en la educación de refugiados y estudiantes que se encuentran en situaciones de urgencia y conflicto. La investigación mostró que la contribución del pensamiento de Freire a una educación liberadora y amorosa y a la construcción de una sociedad colaborativa y acogedora es innegable.

Palabras clave: Freire. Pedagogía crítica. Políticas educativas. Refugiados.

Recebido em 6 de abril de 2020

Aceito em 10 de agosto de 2020

Publicado em 20 de agosto de 2020

\section{INTRODUÇÃO}

De início, é importante esclarecer que nós não nos colocamos como discípulos de Freire. 0 próprio Freire considerou que a crítica a sua obra é uma condição necessária para o seu aprimoramento. Sem que seja um elemento incondicional, consideramos, no entanto, que 
o patrimônio pedagógico internacional de Paulo Freire é necessário nas ciências da educação se quisermos nos equipar com ferramentas úteis para entender, analisar e implementar políticas e processos educacionais contemporâneos emancipadores e capazes de combater as desigualdades.

Nosso interesse pela pedagogia crítica de inspiração freireana está estreitamente ligado à própria natureza do pensamento pedagógico de Paulo Freire. Ou seja, uma obra considera três níveis nos quais se desenvolve toda a pedagogia e todo o processo educativo: a) macro: nível político e ideológico; b) meso: nível das instituições educativas e das lutas que nelas ocorrem; c) micro: nível local onde agem os atores da relação pedagógica. É nesse nível ainda que se realizam a aprendizagem, o ensino da língua e as ações dos estudantes e dos educadores. Evidentemente Freire postula que há nexos estreitos entre esses três níveis, mas na sua obra ele procurou abordá-los sem exceção em diferentes momentos da sua carreira. Assim, no início das atividades de Freire com os oprimidos do Nordeste era a alfabetização sua prioridade, enquanto sua ação político-pedagógica na construção dos sistemas educacionais nas ex-colônias portuguesas da África era no nível macro, no qual se decide o destino dos movimentos de libertação que mais mobilizou Freire.

$\mathrm{Na}$ introdução deste artigo, é importante escrever algumas palavras sobre a pedagogia crítica. Esta considera a educação e o ensino como ações intrinsecamente políticas e rejeita a neutralidade do conhecimento. Ela assevera que as questões de justiça social e de democracia não se distinguem da ação de ensino-aprendizagem. A pedagogia crítica objetiva a emancipação/libertação da opressão e do colonialismo pelo despertar da consciência crítica:

Habits of thought, reading, writing, and speaking which go beneath surface meaning, first impressions, dominant myths, official pronouncements, traditional cliches, received wisdom, and mere opinions, to understand the deep meaning, root causes, social context, ideology, and personal consequences of any action, event, object, process, organization, experience, text, subject matter, policy, mass media, or discourse. (SHOR, 1992, p. 129).

Na primeira parte do artigo, revisitamos certos conceitos fundamentais propostos por Freire. Na segunda parte, é a centralidade da política no trabalho do pedagogo que atrai nossa atenção. A terceira parte do artigo mostra a fertilidade de Freire para uma reflexão sobre a educação dos oprimidos contemporâneos.

Esclarecemos que o método utilizado neste artigo é a hermenêutica, como a encontramos n'0 conflito das interpretações, de Ricoeur (1989). Este autor, fundamentado em Aristóteles, apresenta o que seria para ele a hermenêutica. Diz o filósofo francês que, para Aristóteles, a hermeneia diz respeito a todo discurso significante, pois é a hermeneia que "interpreta a realidade, na medida em que a enunciação é uma expressão do real por 
meio de expressões significantes e do discurso significante." (RICOEUR, 1989, p. 6). Este seria o caminho - método - para compreender e interpretar, por meio da exegese, os textos com os problemas mais gerais da significação e da linguagem.

\section{OS CONCEITOS FUNDANTES DA PEDAGOGIA CRÍTICA DE FREIRE}

É possível dizer que a pedagogia de Freire está baseada em numerosos conceitos. Realizamos uma seleção não exaustiva dos conceitos que nos parecem essenciais na pedagogia crítica: opressão, conscientização, palavras geradoras, círculo de cultura, diálogo, práxis e emancipação.

\subsection{OPRESSÃO}

Acreditamos ser este o conceito originário e o ponto de partida da obra pedagógica de Freire. Mesmo se as democracias liberais postulam a igualdade formal dos cidadãos, Paulo Freire considera que o mundo social é dividido em opressores e oprimidos, entre "classes que oprimem e classes oprimidas." (FREIRE, 1972, p. 134). Os opressores controlam os meios de produção, assim como os recursos econômicos e simbólicos de uma sociedade para colocálos ao seu serviço. A opressão é, assim, antes de tudo, uma opressão capitalista. Mas, a opressão é também simbólica e cultural. 0s opressores creem que os seus saberes, suas representações, seu conhecimento, seu modo de ser e sua visão de mundo são superiores, melhores e devem, voluntariamente, ou pela força, imporem-se aos oprimidos na forma de uma invasão cultural. 0 papel das instituições educativas e escolares é essencial na medida em que servem para classificar ou selecionar os indivíduos e para legitimar os saberes dignos de interesse e de serem transmitidos. Portanto, a escola, para Freire, seria parte interessada da opressão.

Parece-nos que a emergência do pensamento pedagógico de Freire está enraizada na sua experiência direta da opressão sofrida pelos trabalhadores rurais da sua terra natal, Pernambuco, Nordeste do Brasil, espaço geográfico e social que conheceu a presença dos povos autóctones, a ocupação colonial portuguesa, a escravidão e a exploração colonialista e capitalista. Os objetivos do trabalho inicial de Freire com os trabalhadores rurais de Pernambuco foram: 1) conscientização; 2) alfabetização; e 3) pós-alfabetização. 0 domínio 
das técnicas de leitura e escrita era o meio e não a finalidade primeira do trabalho educativo (MAZZA; SPIGOLON, 2018).

Por isso, Paulo Freire defende uma prática pedagógica, uma pedagogia que parta do oprimido, uma pedagogia que "tem de ser forjada com ele e não para ele, enquanto homens ou povos, na luta incessante de recuperação da sua humanidade. Pedagogia que faça da opressão e de suas causas objeto da reflexão dos oprimidos." Seria uma pedagogia da qual "resultará o seu engajamento necessário na luta por sua libertação, em que esta pedagogia se fará e refará." (FREIRE, 1972, p. 20).

Daí Freire trabalhar uma educação e uma alfabetização que rompessem o ciclo da opressão. Evidentemente, a opressão atual exercida pelas categorias sociais de umas sobre as outras é diferente daquela do contexto no qual surgiu e se desenvolveu inicialmente o pensamento pedagógico e social de Freire. A opressão atual é mais sutil. Ela tem suas raízes nos processos globais. Como observa Sepúlveda (2019), o poder político que os opressores exercem se transforma em poder-saber mediante o conhecimento, legitimado também pelas classes populares que podem adotar uma atitude passiva. Elas se dissociam das lutas sociopolíticas, num contexto político vazio, hierarquizado e hegemônico. A escola reproduz esse modelo hegemônico e se coloca ao seu serviço por meio dos programas escolares que estão baseados em normas e valores da cultura dominante que quer controlar os corpos e os espíritos das classes populares.

Por isso, Paulo Freire condena de forma contundente a globalização como discurso ideológico, isto é, de falsa consciência da realidade, visto por ele como uma "malvadeza" perpetrada em particular contra as classes populares: "o discurso ideológico da globalização procura disfarçar que ela vem robustecendo a riqueza de uns poucos e verticalizando a pobreza e a miséria de milhões. 0 sistema capitalista alcança no neoliberalismo globalizante o máximo de eficácia de sua malvadez intrínseca." (FREIRE, 1997, p. 248).

De acordo com Sepúlveda (2019), o poder político que os opressores exercem se transforma em poder-saber mediante o conhecimento, legitimado também pelas classes populares que podem mostrar uma atitude passiva. Elas se dissociam das lutas sociopolíticas no interior de um contexto político vazio, hierarquizado e hegemônico. A escola reproduziu esse modelo hegemônico e se colocou ao seu serviço por meio de programas escolares que estão baseados em normas e valores da cultura dominante que quer controlar os corpos e os espíritos das massas populares. 


\subsection{CONSCIENTIZAÇÃO}

Esse conceito assume em Freire diversas dimensões. Primeiro, a necessidade dos oprimidos de tomarem consciência das múltiplas opressões que são exercidas sobre eles. Em seguida, os oprimidos devem tomar consciência de sua força e capacidade de ação para transformação. Mas essa tomada de consciência só é possivel à medida que os oprimidos se unem e trabalham em conjunto. Porém o conceito freireano de conscientização tem a ver também com os opressores e as elites sociais que devem, voluntariamente, trabalhar contra os interesses de seu próprio grupo social. Trata-se da noção de suicídio de classe que Freire tomou emprestado de Amilcar Cabral e que ele coloca em ação para tornar possível a transformação social apesar de toda a adversidade. Na literatura da pedagogia crítica, a conscientização é necessária para, por exemplo, a fim de que os educadores tomem consciência de seu papel na perpetuação das injustiças ou no combate em prol de uma sociedade mais justa e mais equitativa. Se os atores sociais se conscientizam do seu privilégio de serem homens e mulheres, brancos e brancas, e de fazerem parte da elite social e econômica, podem agir em favor da justiça social. Freire (2006) adverte no seu último livro sobre o perigo e a força do discurso fatalista neoliberal, pragmático e reacionário, assim como a necessidade de colocar a conscientização no centro das políticas educacionais contemporâneas.

De acordo com Freire, a pedagogia não pode, de forma alguma, ser politicamente neutra. Ela não é somente um fato de reprodução das desigualdades sociais e pode, sob certas condições, ser um fator de libertação.

La nature de la pratique éducative, sa nécessité de finalité, les objectifs, les rêves qui en découlent interdisent sa neutralité. La pratique éducative est toujours politique. C'est ce que jappelle la "politisation" de l'enseignement. La nature même de l'enseignement est politique. La question se pose alors de savoir quel type de savoir quel type de politique, en faveur de quoi et de qui, contre quoi et contre qui elle est dirigée. (FREIRE, 1991, p. 23).

A conscientização ocupa um lugar central no pensamento pedagógico de Freire (2012), que distingue três tipos de consciência: 1) consciência mágica; 2) consciência ingênua; e 3) consciência crítica. A consciência mágica caracteriza uma situação na qual o sujeito é incapaz de agir de uma maneira independente e aceita que o seu destino é determinado por forças externas. 0 sujeito não tem consciência das contradições socioeconômicas da sociedade. A consciência ingênua expressa a situação na qual o sujeito tem uma compreensão parcial das relações de poder na sociedade e da existência de relações de força. Mesmo que nesse estágio de consciência o sujeito seja menos dócil, ele permanece pessimista 
sobre a possibilidade de qualquer mudança social. A consciência crítica é caracterizada pelo sujeito que tem consciência que suas possibilidades foram moldadas pelas contradições socioeconômicas. 0 sujeito está consciente, dentro de uma aliança coletiva, do seu poder de mudar seu próprio destino, agindo ao mesmo tempo sobre a estrutura social e sobre o seu próprio pensamento. "A consciência crítica dos oprimidos significa então consciência de si, como 'classe para si'." (FREIRE, 1979, p. 48).

É significativo o fato de que, logo depois de ter fundado o IDAC, em Genebra, juntamente com Claudius Ceccon, Rosiska Darcy de Oliveira e Miguel Darcy de Oliveira, Freire tenha refletido com Ceccon sobre qual seria o sentido que se poderia dar à conscientização depois que, para ele, o vocábulo passou a assumir os mais diversos conceitos. Assim, Paulo Freire o coloca no quadro da ação cultural, da seguinte forma:

A ação cultural para a libertação é a "práxis" das mulheres e dos homens em vista da superação das alienações e limitações às quais eles estão submetidos e sua afirmação enquanto sujeitos conscientes e criadores de seu próprio futuro histórico. A conscientização é o seu método de trabalho. É uma pedagogia politica, uma práxis de libertação que pode ser definida pela oposição que é à educação sistemática tradicional. Esta se baseia na transferência autoritária do saber do professor todo poderoso para os estudantes absolutamente ignorantes. A conscientização ao contrário, se apresenta como um processo educativo em um sentido mais amplo. Ela recusa esta transmissão de um saber acabado. Em uma perspectiva libertadora, a educação é um ato de conhecimento, cujo objeto é o mundo real, a realidade vivida cotidianamente pelas mulheres e os homens que deve ser conhecida e transformada. (CECCON; FREIRE, 1977, p. 1).

Assim, a conscientização assume para Freire um sentido de caminho, de via pedagógica que conduz a uma prática da liberdade, isso porque a educação como "ato de conhecimento" não pode prescindir da conscientização como emersão de uma consciência crítica da realidade.

\subsection{PALAURAS GERADORAS, CÍRCULO DE CULTURA, DIÁLOGO, PRÁXIS E EMANCIPAÇÃO}

A ação educativa desenvolvida por Paulo Freire e sua equipe, em colaboração com os adultos analfabetos, ou semianalfabetos, era constituída de seis fases sucessivas assim identificadas por Freire (1967, p. 11-14) e retrabalhadas por Mazza e Spigolon (2018): 1) uma pesquisa sobre suas condições de vida e a língua utilizada; 2) ampliar o vocabulário dos 
estudantes; 3) coletar as palavras geradoras; 4) enumerar a riqueza silábica dos estudantes; 5) organizar as fichas de cultura (slides, imagens, cartazes) com as representações da natureza e da cultura; e 6) dinamizar os círculos de cultura com os diálogos entre educadores e educandos nutridos com a ideia do ser humano como criador de cultura na relação com a cultura.

Essas diferentes fases mobilizam diversos conceitos que devem ser considerados de uma perspectiva holística para colocar em ação a pedagogia de Freire. Elas exigem uma mudança de paradigma pedagógico baseada em alguns princípios, como:

a) a alfabetização não é somente o acesso ao mundo da escrita ou uma técnica para decifrar as palavras, mas também, e sobretudo, uma porta de entrada ao mundo social a fim de compreender e transformar: ler as palavras e compreender o mundo desigual e injusto ao mesmo tempo. À medida que Paulo Freire coloca um significativo acento sobre a leitura do mundo e a leitura da palavra no processo de alfabetização, a palavra geradora não pode ser "muda, silenciosa, nem pode nutrir-se de falsas palavras, mas de palavras verdadeiras, com as quais os homens e as mulheres transformam o mundo." (FREIRE, 1972, p. 98). Palavras verdadeiras porque se originam no e do universo vocabular e existencial do alfabetizando.

b) Em vez de uma organização pedagógica vertical ou bancária, na qual o educador sabe e o aluno absorve o saber do educador, o educando é passivo, e o educador domina a situação pedagógica, Freire preconiza uma organização fluída e horizontal fundada no diálogo e na interação entre os sujeitos do processo (FREIRE, 1972).

c) Os círculos de cultura são instrumentos privilegiados para o diálogo e para a criação comum dos saberes. A legitimidade dos saberes é múltipla. Os saberes dos oprimidos têm também um valor importante para a aprendizagem. Isso porque os Círculos de Cultura, para Freire, "eram espaços em que dialogicamente se ensinava e se aprendia", constituindo uma relação de dialogicidade, como, continuando, explica Paulo Freire:

eram espaços que se conhecia em lugar de se fazer transferência de conhecimento. Em que se produzia conhecimento em lugar da justaposição ou da superposição de conhecimento feitas pelo educador/a ou sobre o/a educando/a. Em que se construíam novas hipóteses de leitura do mundo. (FREIRE, 1994, p. 155). 
Práxis e emancipação/libertação são conceitos centrais na educação freireana. Freire (1972, p. 93) define a práxis na pedagogia dos oprimidos como "reflexão e ação dirigidas para as estruturas a serem transformadas." Graças à práxis, as pessoas oprimidas podem adquirir uma consciência crítica da sua condição e, com os educadores lou animadores culturais), lutarem pela libertação e pela emancipação.

A concepção freireana de emancipação/libertação é dialética e coletiva, pois, se "ninguém liberta ninguém, nem ninguém se liberta sozinho, os homens se libertam em comunhão" (FREIRE, 1972, p. 25), da mesma forma "ninguém emancipa ninguém, ninguém se emancipa sozinho, é em conjunto que as pessoas se emancipam." (CORNET; DE SMET, 2013, p. 23). Isso porque "[...] a grande tarefa humanística e histórica dos oprimidos é libertarem-se a si mesmos, libertando desta forma os opressores." (FREIRE, 1972, p. 32). A emancipação/ libertação dos oprimidos é condição, portanto, para a própria libertação dos opressores.

A emancipação/libertação é igualmente para Freire um processo de conflito (POUWELS, 2019). Esse ponto nos parece capital na pedagogia crítica, pois os educadores tendem a agir no quadro profissional e étnico e subestimam suas responsabilidades éticas e políticas na perpetuação ou na diminuição das desigualdades escolares.

Concluímos esta primeira parte do artigo que trabalha sobre os conceitos fundantes da pedagogia crítica de Freire, afirmando que ele teve sempre a coragem de enfrentar tanto a teorização da educação quanto a prática pedagógica. Ele chegou mesmo a hesitar ao aceitar a função de responsável dos projetos educacionais do Conselho Mundial de lgrejas em Genebra, ou de ser secretário da educação da Cidade de São Paulo. Comparado com um autor muito conhecido como Jean Piaget, Paulo Freire teve a coragem de fazer idas e vindas entre sua atividade de intelectual/universitária e suas inovações pedagógicas. Destarte, Piaget, que foi professor da Universidade de Genebra por muitas décadas e diretor da Organização Internacional da Educação durante 40 anos, praticamente não fez qualquer nexo entre essas duas funções.

\section{A NECESSIDADE DO POLÍTICO NA REFLEXÃO INTERNACIONAL ATUAL SOBRE A EDUCAÇÃO}

Após percorrer de uma maneira sintética certos conceitos da pedagogia de Freire, acreditamos que seja crucial mostrar que sua teoria é mais do que nunca atual. Por quê?

Como acentua Pereira (2016), o interesse primeiro de Paulo Freire, contrariamente a outras concepções pedagógicas, é que ele defende uma visão da pedagogia que se quer explicitamente engajada contra as relações sociais de dominação. Isso não quer dizer de 
forma alguma que se trata de uma pedagogia exclusivamente adstrita a uma ideologia política particular, mas uma pedagogia engajada na luta contra as relações sociais de dominação. Para Freire (2006, p. 123):

\begin{abstract}
A qualidade de ser política é inerente à essência da educação. Na verdade, a neutralidade da educação é impossivel. Essa impossibilidade não é, contudo determinada pelo fato que os professores são "agitadores" e "subversivos". Da mesma forma, a educação não se torna política por decisão de tal ou tal educador. A educação é política.
\end{abstract}

Um rápido olhar sobre as politicas educacionais nacionais e internacionais atuais para tentar identificar suas prioridades permite avaliar o interesse estratégico pela perspectiva pedagógica de Freire. Depois de duas ou três décadas ao menos, as políticas educacionais nacionais e internacionais se deixaram seduzir pela medida, a avaliação e os resultados da aprendizagem. 0 discurso pode variar um pouco de um país para outro, mas em todos os lugares do mundo ele tem a mesmas características: é necessário amarrar as políticas e as reformas educacionais com "dados comprobatórios". É necessário avaliar os impactos das reformas, desideologizar a educação e considerá-la de uma maneira puramente "científica" e "técnica". Essa visão instrumental e exclusivamente econômica da educação coincide com o sucesso planetário da pesquisa Programa Internacional de Avaliação de Estudantes (PISA) que se tornou o barômetro mundial da qualidade da educação e dos sistemas educacionais.

Ressaltando, em todo caso, que certos resultados da consulta elaborada e difundida pelo PISA e de outras pesquisas baseadas em testes estandardizados são interessantes e úteis, precisamos ficar preocupados com sua hegemonia na orientação das políticas educacionais. Daí, interesse de uma fundamentação em Freire para interpretar ou contestar os resultados da pesquisa PISA. Por exemplo, um dos resultados mais interessantes do PISA está no fato de colocar em evidência que $15-20 \%$ dos jovens de 15 anos não são alfabetizados em muitos países industrializados, a despeito de terem ao menos nove anos de escolarização de qualidade. É necessário problematizar o processo de alfabetização; para Freire a leitura de mundo precede a leitura da palavra (FREIRE, 1972).

Nos países do Sul a porcentagem de jovens alfabetizados depois de nove ou 10 anos de escolarização pode ser bastante fraca.

Recorremos ao pensamento sociopedagógico de Freire (1967, 1972), que nos permite colocar questões imprescindiveis, como:

a) podemos alfabetizar esses jovens mantendo as abordagens pedagógicas tradicionais e bancárias? 
b) Esses jovens estão conscientes do fato de que seu analfabetismo funcional os coloca em uma situação "de incapacitados" (portadores de um "handicap") e os impede de se mobilizarem social e politicamente?

c) Em uma economia de serviço com numerosos empregos precários, os jovens que deixam o sistema escolar sem qualificação ou competências podem constituir uma mão de obra manipulável em benefício e/ou em detrimento de quem?

As políticas educacionais são atualmente tomadas pelas neurociências, a criatividade individual, a inteligência artificial e a revolução digital. Aqui, também, o pensamento de Freire é salutar. Suas ideias pedagógicas e sociais auxiliam a superar o fetichismo digital, desvelando os interesses de mercantilização, de dominação e de opressão que existem por detrás da utilização de nossa dependência da informática e das redes sociais.

A pedagogia de Paulo Freire é uma pedagogia humanista e humanizadora em um período de triunfo da pedagogia instrumental e técnica a serviço da economia: "Não há outro caminho senão o da prática de uma pedagogia humanizadora, em que a liderança revolucionária, em lugar de se sobrepor aos oprimidos e continuar mantendo-os como quase 'coisas', com eles estabelece uma relação dialógica permanente." (FREIRE, 1972, p. 63).

A Figura 1 resume a tensão entre a educação bancária dominante nas políticas educacionais contemporâneas e a pedagogia emancipadora de Freire. Mesmo se Paulo Freire dá prioridade ao contexto social de aprendizagem e pode dar a impressão de negligenciar o objeto do conhecimento, no entanto, no seu último livro, a Pedagogia da autonomia, Freire sugere práticas pedagógicas de educabilidade dos educadores, entre eles e para cada um deles, mas também com os educandos. Ele mostra a importância do diálogo intersubjetivo, apaixonado em torno de um objeto do conhecimento, que deve estar presente em todo o processo educativo.

Se tivéssemos que apreender uma palavra da obra de Freire - complexa e multiforme -, poderia ser, deveria ser, a educação é necessariamente um empreendimento político-pedagógico. Como Carvalho e Pio (2017, p. 441) colocaram muito bem:

Freire propõe uma teoria da ação dialógica, reflexiva e problematizadora que favorece a luta contra propostas de formação/educação enrijecida pela burocracia, pelo dirigismo, distante da realidade, descontextualizada, não passivel de reflexão e verticalizada, desconectada da totalidade dos processos educativos. Instrumentaliza a luta em defesa de processos formativos alçados nos princípios da humanização, os quais devem ultrapassar os muros das instituições incumbidas dessa missão, devem 
abranger a vida em todos os seus aspectos, tendo que favorecer a compreensão de que não se é objeto e sim sujeito.

Essa citação reflete a maneira como o próprio Paulo Freire percebia a educação como um ato político por natureza e, portanto, longe de ser neutra, pois "fazemos a educação a favor de quem e de que, portanto, contra quem e contra o que, desenvolvemos nossa atividade política. Por isso quanto mais temos esta clareza através da prática, mais nos damos conta da impossibilidade de separar o inseparável: a educação da política." (FREIRE, 1987, p. 27).

Para fins de ilustração, a figura a seguir demonstra a tensão entre educação bancária e pedagogia crítica, apresentando as principais características que diferenciam uma perspectiva em relação a outra.

Figura 1 - Tensão entre educação bancária e pedagogia crítica

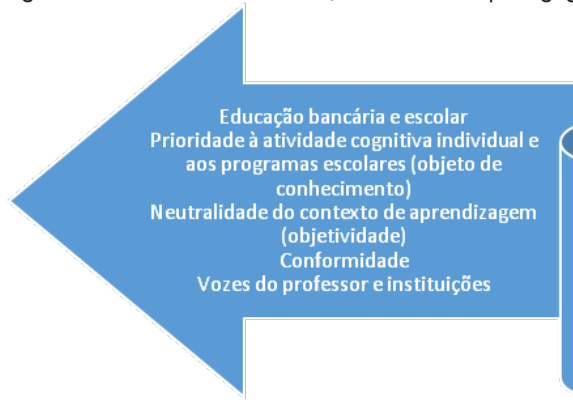

Pedagogia crítica de Freire Práxis = reflexăo e ação (educacional, social e política)

Prioridade aos temas coletivos e de gémérateurs Curiosidade

Falta de neutralidade no contexto de aprendizagem (subjetividade e intersubjetividade) Vozes dos alunos e diálogo autêntico

Fonte: os autores.

\section{A EDUCAÇÃO DOS REFUGIADOS E OS ESTUDANTES NAS SITUAÇÕES DE URGÊNCIA E CONFLITOS}

Nos seus primeiros e últimos escritos, Freire colocou em evidência as condições de criação, com os trabalhadores, os estudantes, os professores, etc., nos seus sindicatos, associações, comunidades, escolas, etc., de uma "outra educação". Uma educação da resistência que não aceita a exploração dos oprimidos, uma educação para a autonomia, uma educação para formar cidadãos de direitos plenos, e não uma educação que forma cidadãos de segunda classe. Uma educação cidadã que combate o cinismo neoliberal globalizado corresponsável pela miséria e pela catástrofe social dos dias atuais (SCOCUGLIA; RÉGNIER, 
2007). Na realidade na obra Pedagogia da indignação, Freire (2000) ataca o que ele chama de maldade neoliberal. A rigor, a orientação do pensamento de Freire durante a última parte da sua vida tem uma pertinência indubitável no contexto atual marcado pelos fluxos de refugiados e de migrantes (AKKARI; RADHOUANE, 2019).

Uma consulta em revistas e em bases de dados acadêmicos mostra quanto a pedagogia de Freire desperta interesse quando se trata da educação dos refugiados, que Freire chamaria de "esfarrapados da terra", isto é, aqueles que diante de "situações-limite" precisam buscar o "inédito viável." (FREIRE, 1972).

A Europa, assim como outras regiões do mundo, está sendo confrontada, depois de alguns anos, com a chegada maciça de numerosos refugiados políticos, econômicos ou climáticos. Ora, muitos autores encontram uma forte inspiração no pensamento de Freire para responder às necessidades educacionais específicas dos refugiados. Se Paulo Freire estivesse fisicamente presente entre nós, ele certamente insistiria sobre os fatores estruturais que levam milhares de indivíduos a deixarem seus países de origem: imperialismo, poderes autoritários e cumplicidade de um capitalismo selvagem e globalizado, guerras pós-coloniais.

An important aspect of a subaltern pedagogical framework is the educator's awareness of the social and political circumstances that affect our migrant students' lived experiences and how to teach to those who have transcended borders and face race, class, and gender discrimination and economic hardship in the new country. (KEYEL, 2017, p. 186).

As instituições encarregadas de facilitar a integração social e linguística dos refugiados reclamam da falta de eficácia dos cursos de alfabetização. Com efeito, a maior parte do tempo. 0s refugiados não podem se expressar na língua do país que os acolhe a despeito de terem seguido inúmeros cursos. Ora, amiúde as ações pedagógicas levadas a efeito nos cursos não correspondem à vida, às competências, às experiências, às emoções e aos interesses dos estudantes refugiados. Parece-nos certo que os cursos de alfabetização poderiam obter sucesso se utilizassem os temas e as palavras geradoras do "método" freireano e a pedagogia de Freire. Aliás, na Alemanha, e provavelmente em outras partes do mundo, os pedagogos se inspiram na pedagogia crítica de Paulo Freire e nas suas palavras geradoras para propor aos refugiados cursos de alfabetização mais pertinentes. A pedagogia da esperança de Freire tem potencial para transformar a educação dos refugiados (MAADAD, 2019; ORLANDO; MESQUIDA; BORGES, 2019).

Segundo Couch (2017), a pedagogia crítica desenvolvida por Freire pode ser aplicada no contexto da Birmânia em razão de sua sinergia intemporal entre os contextos de transição do Brasil dos anos de 1960/70 e a luta atual dos oprimidos daquele país. Freire descreveu 
- Brasil como uma "sociedade em trânsito", ou uma "sociedade fechada e dividida" entre os diferentes grupos de interesse: a pequena elite social e as massas de pessoas submersas na miséria (FREIRE, 2003). A falta de consciência crítica ou de experiência democrática está na raiz do hábito de submissão e de adaptação à submissão. Essa análise de Freire se adéqua à opressão que se mostra atualmente na Birmânia e na fronteira birmaniana.

Magee e Pherali (2019) analisaram um programa de educação alternativa trabalhado com os refugiados sírios na Jordânia. Esse programa dá um exemplo perspicaz de uma prática educativa alternativa para ser desenvolvida entre os refugiados, acentuando a ideia de consciência, de respeito mútuo e de dignidade, oferecendo, ao final, um certificado. A aprendizagem no quadro do programa pode oferecer uma esperança de um meio de subsistência estável em curto e médio tempos. No entanto, esta pesquisa revelou também que as pedagogias transformadoras alimentadas pela noção freireana de consciência crítica para os jovens refugiados sírios na Jordânia são deformadas por uma série de fatores.

A percepção de que a conscientização é contrária ao objetivo de obter certificado pode reduzir o programa alternativo a uma cópia da escola formal e acrítica. Mais ainda, o risco de repatriamento eventual na Síria ou as possibilidades de emprego em outros lugares podem levar os refugiados a utilizar os espaços escolares ao isolamento da sociedade jordaniana e a formação de microcomunidades sírias antes de engajamentos coletivos coordenados com a comunidade que os acolhe.

A ancoragem no pensamento de Freire $(1967,1972)$ permite uma análise crítica da alienação contemporânea dos jovens. As noções de objetivação, de opressão e de libertação são particularmente úteis para tentar dar um sentido aos jovens de sua alienação e ao desinteresse que numerosos estudantes têm pela escola. 0 consumo de drogas, a gravidez precoce entre as adolescentes, o fenômeno das gangues, o abandono da escola, o suicídio, a violência e a apatia política podem ser considerados como manifestações simbólicas de uma juventude que mostra seu distanciamento da escolarização. Giroux (1996) chama a atenção para o pânico moral gerado pelo discurso diabolizante da identidade dos jovens e lembra que a pedagogia de Freire pode favorecer a consciência crítica, mantendo um diálogo com os jovens sobre suas preocupações cotidianas e os encorajando a relacionarem essas preocupações com as estruturas e com as relações sociais de exploração (MCINERNEY, 2009).

Para Delvaux e Delvaux (2012), quatro posturas estão associadas a todo projeto educacional emancipador:

a) a postura de "situar-se" que se encontra na interseção da dimensão de "compreender" e daquela de "sujeito". Ela remete à construção identitária da 
pessoa, mas também à sua capacidade de se posicionar diante dos outros e de se situar no seu meio social e cultural.

b) A postura de "se deslocar" permite colocar em questão os esquemas de compreensão do mundo pela confrontação dos pontos de vista que levam o sujeito a assumir um novo posicionamento em relação às suas convicções iniciais.

c) A postura de "se engajar" coloca antes de tudo a necessidade de fazer parte da transformação social.

d) A postura de "se aliar" se desloca entre o polo do "compreender" e aquele do "ator" e remete à necessária colocação em rede da ação coletiva.

A pedagogia crítica de inspiração freireana está representada perfeitamente nessas posturas propostas por Delvaux e Delvaux (2012). A rigor, todo educador e todo educando devem se situar na rede de relações sociais e serem capazes de compreender os mecanismos e os processos de desigualdade e como operam na escola e na sociedade. A postura de se deslocar exige uma capacidade, tanto dos educandos quanto dos educadores de se colocarem no lugar do outro, de serem sensíveis aos pontos de vista da alteridade. Essa postura influencia igualmente as diferentes etapas do processo pedagógico e a necessidade de adotar uma posição apropriada de acordo com as etapas.

A postura do engajamento está no coração da obra de Paulo Freire, o qual continuamente se engajou em todas as lutas em favor dos oprimidos, desde suas ações pedagógico-sociais no Sesi-Recife, na década de 1950, como ele comenta na obra Aprendendo com a própria história (FREIRE; GUIMARÃES, 2013). Assim, é importante superar a visão instrumental da educação, isto é, estar prioritariamente a serviço da economia, para ir na direção de uma visão/ação humanista da educação que prioriza a mudança social. Como mostra Broussal (2019, p. 48), “a emancipação não poderia ser uma preocupação secundária, mesmo opcional, da formação de adultos. Sem negligenciar a importância da dimensão produtiva, toda formação deveria ter o cuidado de se preocupar com a maneira como ela contribui para a emancipação dos formados." A postura de se aliar é da mesma forma central na obra de Freire. Em particular, a aliança entre os oprimidos e os intelectuais progressistas para construir uma educação diferente e mais justa. 
Figura 2 - Avaliação do processo de emancipação

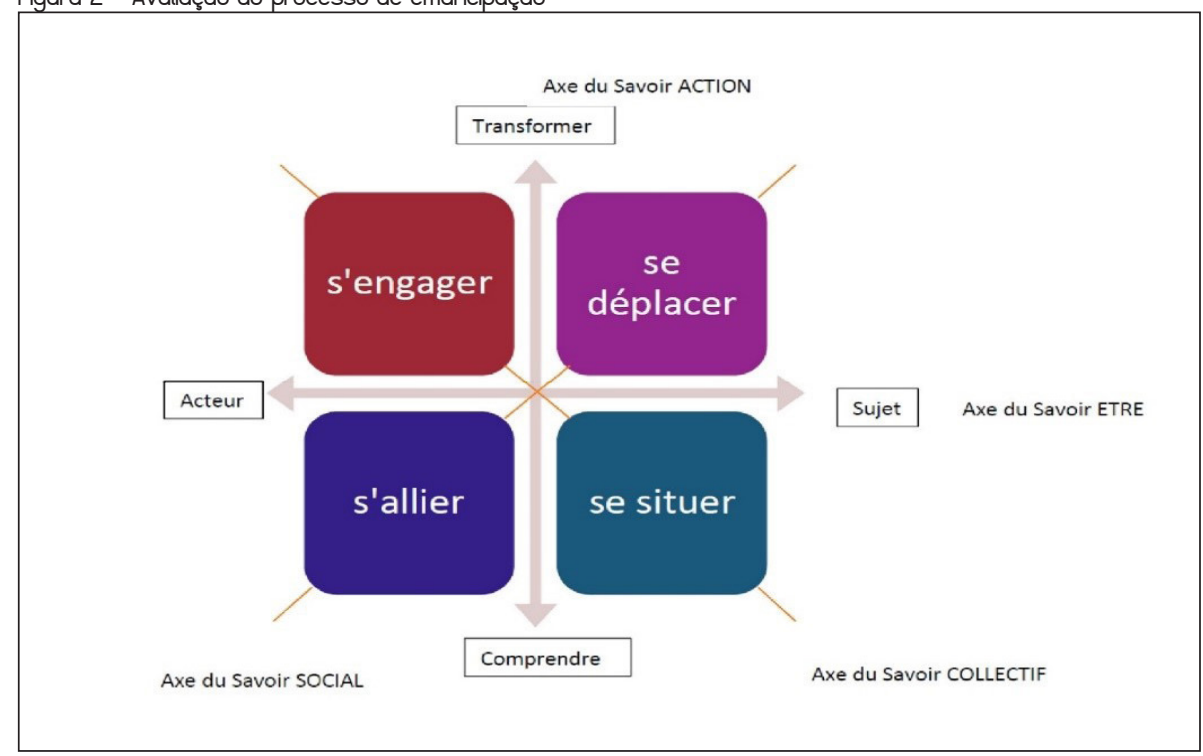

Fonte: Delvaux e Delvaux (2012)

A Figura 2 sintetiza nossa argumentação no que tange à avaliação do processo de emancipação, ao estabelecer quatro disposições do saber (saber fazer, saber ser, saber social e saber coletivo) que se mobilizam mediante o engajamento, a mobilização, a aliança e a conscientização entre os sujeitos/atores, para que, então, a realidade possa ser compreendida e transformada.

\section{CONCLUSÃO: A MAIS IMPORTANTE CONTRIBUIÇÃO DE FREIRE PARA A PEDAGOGIA CONTEMPORÂNEA}

Quando a pedagogia de Freire está sendo tão atacada, denegrida e combatida no seu país de origem, é importante que possamos em nível internacional reatualizar sua obra, difundir, revisitar e criticar seus conceitos pedagógicos. Como afirma Giroux (2016), a pedagogia de Freire expressa a coragem de afirmar o político.

Dar voz aos educandos, em especial aos mais vulneráveis, subalternos e oprimidos, é o sentido maior da pedagogia de Paulo Freire. Darder (2017) colocou magnificamente em evidência a contribuição de Freire, ressaltando a maneira como a pedagogia do amor de Freire pode inspirar, na teoria e na prática, um enfoque humanista do ensino e da aprendizagem. 
Poderosos relatos de professores oferecem exemplos de uma prática viva, engajada em uma vida de classe democrática e na emancipação das comunidades subalternas e oprimidas. Os relatos ilustram com clareza como as ideias de Paulo Freire podem ser praticadas nas escolas e nas comunidades nos dias de hoje.

0 mais importante livro pedagógico de Freire, a Pedagogia do oprimido, é uma referência mundial da pedagogia, sendo a terceira publicação mais citada nas produções das ciências humanas (GREEN, 2016). 0 mapa a seguir mostra a difusão mundial da obra de Freire e também como ela freia as ditaduras e avança com a democratização. No contexto atual da globalização, necessitamos dessa obra pedagógica que batalha por um mundo menos desigual (MARIN, 2019).

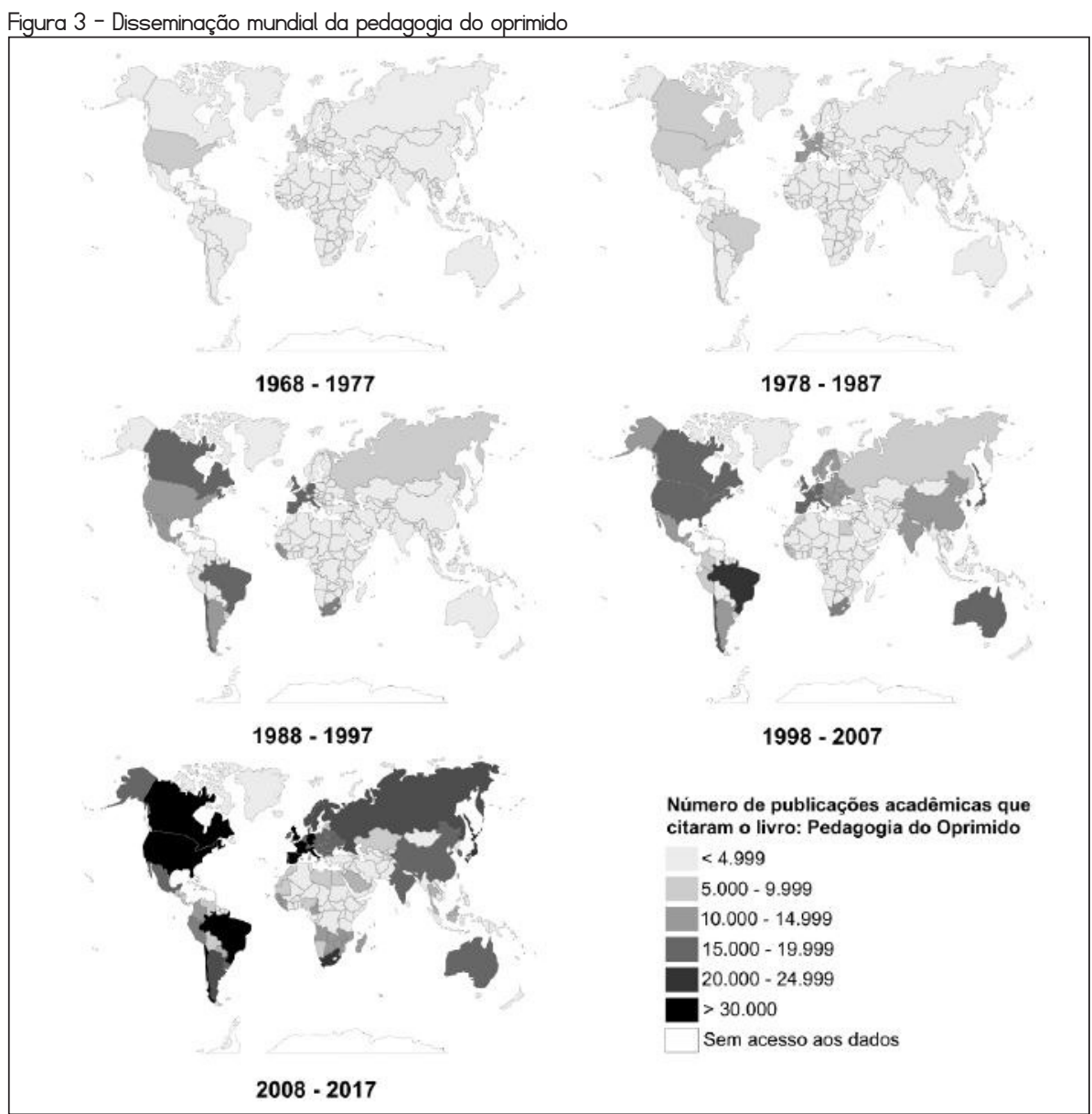

Fonte: Santana e Souza (2019). 
A vida e a obra de Paulo Freire foram tomando forma em diferentes espaços e tempos dos quais alguns se situam nas Américas: Brasil, Bolívia, Chile e Estados Unidos; na Europa: Suíça; e em outros espaços geográficos onde Freire atuou profissionalmente - África: Guiné Bissau, Cabo Verde e São Tomé e Príncipe (MAZZA; SPIGOLON, 2018; FREIRE; GUIMARÃES, 2013). Para Freire (1978, p. 56), a África foi particularmente importante para forjar sua trajetória internacional:

\footnotetext{
Todas as atividades que eu desenvolvi na África significam muito para mim e para aqueles que trabalham comigo. Como eu digo no meu livro, esses países da África me dão a possibilidade de me reencontrar de novo comigo mesmo, e se eu tivesse morrido antes de me reencontrar comigo mesmo por meio da África, eu teria morrido com um vazio na minha experiência existencial. Esses paises me deram a possibilidade de preencher esse vazio antes de morrer. Não se trata de puro sentimentalismo. Isso tem muito a ver com a minha reaprendizagem, eu fui levado a re-conhecer mais o que eu já conhecia e cada vez que reconheces tu conheces melhor. Toda esta experiência que se expressa aqui pelo traço de união de re-conhecer é capital para mim mesmo e para meus companheiros.
}

Em um período no qual as políticas educacionais se reduzem a slogans, como "aumentar a performance dos alunos na SAIEB, ou no ENEM no Brasil", ou "melhorar a classificação do Brasil no PISA", a pedagogia de Freire nos lembra que o essencial da educação são suas finalidades. Dito de outra forma, qual sociedade queremos, uma sociedade mais justa, solidária e mais igualitária ou uma sociedade competitiva e produtiva? É, por isso mesmo, importante considerar que a escola não tem por tarefa principal fornecer uma mão de obra dócil e produtiva para a economia, mas, sim, formar cidadãos, claro, competentes e abertos à cultura escrita, à ciência e à racionalidade, mas também indivíduos que se preocupam com as desigualdades, sejam dos que lhe são próximos, sejam dos que estão longe, bem como com o futuro do nosso Planeta.

A pedagogia emancipadora e crítica de inspiração freireana é uma ferramenta útil para nos ajudar a formar as gerações futuras. 0 mundo jamais esteve tão conectado e globalizado, mas, ao mesmo tempo, ele está marcado por uma cultura de ódio contra as categorias sociais mais frágeis. No entanto, a pedagogia política lúcida de Freire é capaz de possibilitar uma pedagogia lúcida do amor. 


\section{REFERÊNCIAS}

AKKARI, A.; RADHOUANE, M. La traversée des exclus à la lumière de la pédagogie Freire: un regard sur la dynamique migratoire entre l'Afrique et l'Europe. In: ORLANDO, E. de A.; MESQUIDA, P.; BORGES, V. (org.). Os refugiados da terra: uma problemática ético-política inspirada nas abordagens freireanas. Curtiba, PR: Editora CRV, 2019. p. 73-87.

BROUSSAL, D. Émancipation et formation: une alliance en question. Savoirs, [s. l.], n. 3, p. 13-58, 2019.

CARVALHO, S. M. G. D.; PIO, P. M. A categoria da práxis em Pedagogia do Oprimido: sentidos e implicações para a educação libertadora. Revista Brasileira de Estudos Pedagógicos, [s. l.], v. 98, n. 249, p. 428445, 2017.

CECCON, C.; FREIRE, P. Conscientisation et révolution: une conversation avec Paulo Freire. Genève: IDAC, 1977.

CORNET, J.; DE SMET, N. Enseigner pour émanciper, émanciper pour apprendre. Une autre conception du groupe - classe. Paris: ESF, 2013.

COUCH, J. On the borders of Pedagogy: Implementing a critical pedagogy for students on the Thai Burma Border. Australian Journal of Adult Learning, [s. l., v. 57, n. 1, p. 126, 2017.

DARDER, A. Reinventing Paulo Freire: A pedagogy of love. New York: Routledge, 2017.

DELVAUX, V.; DELVAUX, E. Évaluer l'émancipation dans une formation. Le cas de l'sco. Le Grain. Atelier de pédagogie sociale, 2012. Disponivel em: http://www.legrainasbl.org. Acesso em: 27 fev. 2020.

FREIRE, P. Ação cultural para a liberdade. Rio de Janeiro: Paz e Terra, 1979.

FREIRE, P. A importância do ato de ler; em três artigos que se completam. São Paulo: Autores Associados: Cortez, 1987.

FREIRE, P. Educação como prática da liberdade. Rio de Janeiro: Paz e Terra, 1967.

FREIRE, P. Educação e atualidade brasileira. São Paulo: Ed. Cortez, 2003.

FREIRE, P. Eduction for critical conscienciouness. London et New York: Continuum Press, 2012.

FREIRE, P. Entretien avec Paulo Freire. 1978. Disponivel em: https://www.cndf-paulofreire.org/wp-content/uploads/2018/08/Entretien_avec_Paulo_Freire.pdf. Acesso em: 27 fev. 2020.

FREIRE, P. Globalização, ética e solidariedade. In: DOWBOR, L.; IANNI, 0.; RESENDE, P.-E. Desafios da globalização. Petrópolis: Vozes, 1997.

FREIRE, P.; GUIMARÃES. Aprendendo com a própria história. São Paulo: Editora Unesp, 2013. 
FREIRE, P. L'Éducation dans la ville. Paris: Éditions Paideia, 1991.

FREIRE, P. Pedagogia da Esperança. Um reencontro com a Pedagogia do oprimido. Rio de Janeiro: Paz e Terra, 1994.

FREIRE, P. Pedagogia da indignação: cartas pedagógicas e outros escritos. São Paulo: Editora Unesp, 2000.

FREIRE, P. Pedagogia do oprimido. Porto: Afrontamento, 1972.

FREIRE, P. Pédagogie de l'autonomie. Toulouse: E'ditions Erès, 2006.

GIROUX, H. A. Critical Pedagogy, Paulo Freire and the courage to be political. Revista E-Curriculum, [s. l], v. 14, n. 1, p. 296-306, 2016.

GIROUX, H. A. Fugitive cultures: Race, violence and youth. New York \& London: Routledge, 1996.

GREEN, E. What are the most-cited publications in the social sciences (according to Google Scholar)? Impact of social sciences. London: Blog, London School of Economics, 2016.

KEYEL, S. Subaltern Pedagogy: A Critical Theorizing of Pedagogical Practices for Marginalized BorderCrossers. The International Journal of Critical Pedagogy, [s. l.], v. 8, n. 1, p. 173-194, 2017.

MAADAD, N. Syrian Refugee Children in Australia and Sweden: Education and Survival Among the Displaced, Dispossessed and Disrupted. New York: Routledge, 2019.

MAGEE, A.; PHERALI, T. Freirean critical consciousness in a refugee context: a case study of Syrian refugees in Jordan. Compare: A Journal of Comparative and International Education, [s. l., v. 49, n. 2, p. 266-282, 2019.

MARIN, J. Decolonialidade do poder no cotexto da globalizacao. Geografia. Ambiente, Educação e Sociedades, [s. l.], v. 2, n. 1, p. 46-60, 2019.

MAZZA, D.; SPIGOLON, N. I. Educação, exílio e revolução: o camarada Paulo Freire. Revista Brasileira de Pesquisa (Auto) biográfica, [s. l.], v. 3, n. 7, p. 203-220, 2018.

MCINERNEY, P. Toward a critical pedagogy of engagement for alienated youth: insights from Freire and school $\square$ based research. Critical Studies in Education, [s. l.], n. 50, v. 1, p. 23-35, 2009.

ORLANDO, E. A.; MESQUIDA, P.; BORGES, V. (org.). Os refugiados da terra: uma problemática ético-política inspiradas nas abordagens freireanas. Curitiba: Editora CRV, 2019. 
PEREIRA, I. Paulo Freire: une conscience sociale critique en pédagogie-Questions de classe(s). 2016. Disponivel em: https://www.questionsdeclasses.org/?PPaulo-Freire-une-conscience-sociale-critique-en-pedagogie. Acesso em: 27 fev. 2020.

POUWELS, J. We are in need of each other. Paulo Freire and the role of conflicts in education. International Journal of Social Pedagogy, [s. l., p. 1-15, 2019.

RICOEUR, P. 0 conflito das interpretações: ensaios de hermenêutica. Porto: Rés-Editora, 1989.

SANTANA, O. A.; SOUZA, S. C. D. Pedagogia do Oprimido como referência: 50 anos de dados geo-históricos (1968-2017) E o perfil de seu leitor. História da Educação, [s. l.], v. 23, p. 1-31, 2019.

SCOCUGLIA, A. C.; RÉGNIER, J. C. Origines et évolutions de la pensée politico-pédagogique de Paulo Freire. Reliance, [s. l., n. 4, p. 103-108, 2007.

SEPÚLVEDA, C. 0. L'école comme outil de transformation sociale: de la domination vers une pédagogie pour la libération et la participation démocratique. Specificites, [s. l., n. 2, p. 246-252, 2019.

SHOR, I. Empowering education: critical teaching for social change. Chicago: University of Chicago Press, 1992.

Endereços para correspondência: Abdeljalil Akkari. Université de Genève, UNI MAlL FPSE, 40 bd du Pont-d'Arve, CH-१२११, Genève 4, Suisse; abdeljalil.akkari@unige.ch

Roteiro, Joaçaba, U. 45, p. 1-22, jan./ dez. 2020 | e23948 |E-ISSN 2177-6059 
